\title{
The Views and Knowledge of Parents of Children with Speech/Language Disorders on Speech and Language Therapy in Turkey
}

\author{
Ayşe Aydın Uysal* and Gülşah Tura \\ Department of Special Education, Kocaeli University, Turkey \\ *Corresponding author: Ayșe Aydın Uysal, Department of Special Education, Kocaeli University, Turkey
}

Submission: 門December 05, 2018; Published: 些 January 09, 2019

\begin{abstract}
The aim of this study is to investigate the views and knowledge of parents of children with speech and language disorders on speech and language therapy. A total of 189 surveys were completed through a questionnaire about their knowledge of the field of speech and language therapy and communication disorders. The views and knowledge of parents of children with speech/language disorders on speech and language therapy was limited. 85.9\% of the participants indicated that they had never read anything about SLPs. Of those who had read about SLPs $16.1 \%$ reported that hat they have obtained the related information through television and $12.5 \%$ internet.
\end{abstract}

\section{Introduction}

Families play a major role in supporting children's cognitive, social and linguistic development and has a long-lasting impact on their life [1]. Speech and language therapy, the study of human communication and disorders, is one of the health disciplines in which family involvement is a requirement in the prevention, during the therapy or the maintenance phases of the acquired abilities. Since children spend the majority of their time with their families, parents or caregivers are essential part of their child's communication environment and have more opportunities to interact with their child in daily situations than any speech and language therapist does. So, the role of parents in the early detection of the speech and language disorders are very important for early intervention which will have a huge effect on the child's language abilities, cognitive and social development. Moreover, after special need is detected and the child started to therapy, behaviours learned in the therapy sessions can be generalised into home and other social environments via parents. Recent research also supports the notion that children whose parents attend to therapy sessions and involve at home make a greater improvement compared to children whose parents do not involve [2].

The speech-language pathology is a new area in Turkey. Medical specialists, psychologists, special educators were expected to provide speech and language therapy services until the foundation of this distinct and independent discipline. The delivery of service to the people with speech and language disorders is carried by speech and language therapists as in the developed countries after the foundation of graduate and postgraduate programs. Although the number of graduate students in this area increases with more departments founded in numerous universities in Turkey, there's still need for families to learn about this new profession and the distinctive role of SLT among other professions which carried speech and language therapy services before [3].

With the increasing number of children diagnosed with speech and language disorders, the number of parents seeking information about the diagnosis and intervention for their children also increase. Parental experiences of children with speech and language disorders show that they are usually not aware of the nature of speech and language problems of children or the importance of being active participant of their children's therapy process [4]. One of the first steps of improving family awareness and engagement to speech and language therapies is to improve their knowledge about these disorders and this new profession in Turkey. This will help to develop family education programmes designed specifically for these families and by turn to improve therapy success. To our knowledge, there's not any study exploring the views and knowledge levels of parents of children with speech/ language disorders on speech and language therapy services in Turkey. Thus, the aim of this study is to investigate the knowledge levels of parents/caregivers of children with speech and language disorders between the ages of three and fifteen years, regarding speech and language therapy services in Turkey.

\section{Method}

\section{Questionnaire design}

The original questionnaire that was developed in English, by Breadner et al. [5] was translated into Turkish. The questionnaire 
consists of three sections and includes participants' demographics information, their knowledge and awareness of the speech and language therapy and the profession of the speech and language therapist. Knowledge related to when and with whom children should be referred to a speech and language therapist is also included in the questionnaire. The last part of the questionnaire asks questions about the types of communication disorders within the scope of speech and language therapy both in a closed ended question and within a scenario for diverse kinds of communication disorders.

\section{Procedure}

Questionnaires were given out to participants who applied to hospitals with speech and language disorders both in the east and western parts of Turkey. Informed consents of all the participants were collected. Descriptive statistics was used to analyse the data with SPSS statistical analysis software.

\section{Result}

\section{Demographics of the participants}

A total of 189 surveys were completed. Majority of the participants were females (83.1\%). \%44 of the participants had a high school certification, \%19.8 had a bachelor's degree and \%33.9 had elementary school diploma. Nearly half of the participants had an annual income between 2000-3000 Turkish liras, \%42.2 had less than 2000 Turkish liras, \%7.4 was earning between 3000 and 4000 Turkish liras and the other 1.1\% was earning between 4000-5000. More than half of the participants (69.3\%) indicated that they were interested in learning more about the speech and language therapy and wanted to work in the field (Table 1).

Table 1: Demographic characteristics of the sample.

\begin{tabular}{|c|c|c|c|}
\hline Variable & Category & Frequency & $\%$ \\
\hline \multirow{2}{*}{ Gender } & Males & 32 & 16.9 \\
\hline & Females & 157 & 83.1 \\
\hline \multirow{7}{*}{ Age } & $18-25$ & 6 & 3.3 \\
\hline & $26-30$ & 6 & 3.3 \\
\hline & $31-35$ & 17 & 9.2 \\
\hline & $36-40$ & 103 & 56 \\
\hline & $41-45$ & 52 & 28.3 \\
\hline & $46-50$ & 0 & 0 \\
\hline & Above 50 & 0 & 0 \\
\hline \multirow[b]{3}{*}{ Qualification } & $\begin{array}{c}\text { Less than high school } \\
\text { degree }\end{array}$ & 65 & 33.9 \\
\hline & High school degree & 85 & 44.3 \\
\hline & Bachelor degree & 38 & 19.8 \\
\hline
\end{tabular}

\begin{tabular}{|c|c|c|c|}
\hline \multirow{4}{*}{$\begin{array}{c}\text { Total Family } \\
\text { Income }\end{array}$} & Less than $2000 \mathrm{TL}$ & 81 & 42.2 \\
\cline { 2 - 4 } & $2000-3000 \mathrm{TL}$ & 91 & 47.4 \\
\cline { 2 - 4 } & $3000-4000 \mathrm{TL}$ & 14 & 7.3 \\
\cline { 2 - 4 } & $4000-5000 \mathrm{TL}$ & 2 & 1 \\
\hline
\end{tabular}

General knowledge and awareness in the field of speechlanguage pathology

Knowledge about speech language therapists, working settings and clinical training: Regarding the question of whether participants ever read, or heard about speech language therapists, $85.9 \%$ of the participants indicated that they had never read anything about SLPs. Of those who had read about SLPs $16.1 \%$ reported that hat they have obtained the related information through television and $12.5 \%$ internet. Radio, lectures and the parents of the other children who have speech and language disorders were ranked as the lowest sources of information. About $90.6 \%$ of the participants reported that they have never met a speech-language therapist, and $94.8 \%$ reported to know someone who know a SLT. \%93.2 of the participants thought that the speech and language therapist's primary employment setting is hospitals while $81.3 \%$ of the participants believed that SLT can work in the private clinic. Minority of the participants believed that SLT may work in kindergartens (6.8\%) and schools (1.9\%) Interestingly, only $17.2 \%$ of the sample believed that the speech-language pathologist can work in a university setting. 177 of the sample (92.2\%) indicated that they are not referred to an SLT by their family doctor for speech and language assessments. Majority of the participants (85.9\%) thought that the SLT work with adolescents and children (71.9). Few of the participants believed that a SLP is involved in working with infants (0.5\%) and elderly groups (6.8\%). $27.1 \%$ of the participants thought that 3-4-year training after graduation is needed while only $7.6 \%$ of the study participants need 5 or more years education. Only $14.6 \%$ of the sample thought that a SLP can be given the "Doctor" title and the majority believed that the SLP should be called as a "Therapist."

Participants were asked to make judgements on five different communication disorder scenarios including articulation disorders, fluency disorders, language developmental delay, voice disorders, and dyslexia. Majority of the participants believed the importance of the SLPs in the assessment of fluency disorders (95.9\% agreed) and articulation disorders (94.3\%). However, language disorders, voice disorders, and dyslexia were the areas that participants were most undecided about. When people are asked to check the listed disorders, they think that should be treated by a speech and language pathologist fluency disorders (96.4\%) and cleft lip and palate $(84.4 \%)$ were the most frequently rated speech and language disorders respectively (Table 2 ). 
Table 2: Participants percentage ratings regarding diversity of disorders treated by speech language pathologists.

\begin{tabular}{|c|c|c|}
\hline & Frequency & $\%$ \\
\hline People with diseases or injuries of the brain & 7 & 3.6 \\
\hline People with hearing loss & 157 & 81.8 \\
\hline People who stutter & 185 & 96.4 \\
\hline Autistic children & 5 & 2.6 \\
\hline People with pneumonia & 2 & 1 \\
\hline Mentally retarded people & 7 & 3.6 \\
\hline People who have their voice & 138 & 71.9 \\
\hline box or vocal folds removed & & \\
\hline People who have had strokes & 3 & 1.6 \\
\hline Adults who lose their eyesight & 1 & 0.5 \\
\hline People with cleft palate or lip & 162 & 84.4 \\
\hline People with strained voices & 27 & 14.1 \\
\hline People with leukemia & 41 & 21.4 \\
\hline People who have memory deficit & 26 & 13.5 \\
\hline People with muscles diseases & 24 & 12.5 \\
\hline People with tonsillitis & 113 & 58.9 \\
\hline
\end{tabular}

\section{Discussion}

The findings of the study revealed that general knowledge and awareness levels of parents of children with speech/language disorders on speech and language therapy as a profession is low. $85.9 \%$ of the participants reported they have never been informed about speech and language therapy via any sources. $16.1 \%$ of parents indicate that they have learned about this profession via television and $12.5 \%$ through internet. This can be related to educational level of the parents in the sample. The mean years of education and SES status in the sample was low.

Parents face with an ever-expanding wealth of information regarding speech and language disorders when trying to find out their children's needs. Internet websites have many advantages while accessing to related information but most of this information on websites are not reliable or hard for parents to sort through them. Moreover, financial restraints put lower-income parents at a disadvantageous position in terms of accessing to internet. Films, videos and public spot ads may be the alternative information sources for learning about speech and language disorders through television especially for the illeteral families and who do not have access to internet.

Another interesting finding of the study was that more than half of the parents in the sample believe that speech and language therapists should be involved in the team when children have speech sound disorders or stuttering when presented with case examples while the majority were neutral or not agree about the role of speech and language therapist in the voice disorders examples, delayed speech or dyslexia. When the disorders are presented within a list and asked to check the ones, they think SLT have a role in the treatment of the disorders, most of the sample (96.4\%) think that they should be involved in the stuttering, people with cleft lip and palate (84.4\%) and hearing loss (81.8\%). These results show that they are not aware of the other groups SLT work with.

Importance and emphasis should be given to these disorders when planning public awareness and parent education programmes. Local departments of health and education, and leading organisations in speech and language therapy, should partner with training organisations, public advocacy groups, and service providers to promote public awareness of the signs, symptoms, and treatment of speech and language disorders in these regions. Most of the participants in the sample indicated that they were not referred by their family doctor to speech and language therapy services. Because of the early age of the profession of SLT in Turkey, family doctors are another group to be informed about speech and language therapy services in Turkey.

Since the role of family doctors is very important in early identification of and intervention for speech, language and literacy delays, increasing the knowledge and awareness levels of this group will help to minimize the time between when children can receive speech/language therapy and when they are receiving. Family doctors have a critical role in reducing this gap and improving long-term outcomes related to speech and language development of the children. The need for team collaboration is inevitable when working with people with speech and language disorders. Scope of practice for family doctors in this field includes early and accurate identification of speech and language delays as well as children at risk for literacy challenges; appropriate referral to speech and language services when required; and teaching and, thus, empowering parents to create rich and responsive language environments at home [6].

Overall results of the study show that knowledge and awareness levels of parents of children with speech/language disorders on speech and language therapy is limited. Parent education and awareness programmes designed for this purpose should focus on increasing the knowledge levels about SLT profession and the scope of groups they work with; especially about dyslexia, voice disorders and dysfagia, the importance of early diagnosis and intervention programmes and the effects of parental involvement on therapy [7]. The study has some limitations. Future studies with larger number of participants examining parent's knowledge and awareness levels in relation to children's diagnosis will also help to identify specific needs of these groups. The comparison of knowledge and awareness levels of mothers and fathers can be another interesting topic to search. Finally, this study investigated parents of children three to fifteen [8]. Future studies can also be conducted to see the differences between parents of different age groups.

\section{References}

1. Borkowski JG, Ramey SL, Bristol PM (2002) Parenting and the child's world: Influences on academic, intellectual, and social-emotional development. Lawrence Erlbaum Associates, Mahwah, New Jersey, USA. 
2. Roberts M, Kaiser A (2011) The Effectiveness of parent-implemented language intervention: a meta-analysis. American Journal of Speech-Language Pathology 20: 180-199.

3. Topbas S (2006) A turkish perspective on communication disorders. Logopedics Phoniatrics Vocology 31(2): 76-88.

4. Rannard A, Lyons C, Glenn S (2004) Children with specific language impairment: parental accounts of the early years. Child Health Care 8: 165-176.

5. Breadner BW, Warr Lecper GA, Husband SJ (1989) A study of public awareness of speech-language pathology: then and now. Human communication Canada 11(2): 5-15.
6. Moharir M, Barnett N, Taras J, Cole M, Ford-Jones EL, et al. (2014) Speech and language support: how physicians can identify and treat speech and language delays in the office setting. Paediatr Child Health 19(1): 13-18.

7. American Speech-Language-Hearing Association (2016) Scope of practice in speech-language pathology.

8. Julie M, Juliet G, Julie P (2007) International Journal of Language and Communication Disorders 42(5): 533-555.

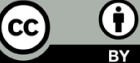

Creative Commons Attribution 4.0 International License

For possible submissions Click Here
Submit Article

Examines in Physical Medicine and Rehabilitation:
Open Access
Benefits of Publishing with us

